\title{
THROMBOEMBOLIC COMPLICATIONS DURING AND AFTER CORTISONE AND ACTH THERAPY
}

\author{
By S. Fazlullah, M.B. (Osmania), D.T.M. \& H. \\ Medical Registrar, Barrow-in-Furness group of Hospitals, Lancashire
}

Now cortisone is available to be prescribed freely by doctors in the Unied Kingdom, it is considered justifiable to report thromboembolic complications during and after cessation of cortisone and ACTH therapy.

These complications may not be serious but may be fatal due to sudden unpredictable pulmonary embolism.

In the presented clinical material, thromboembolic complications were observed during cortisone therapy, and after termination of ACTH. Three patients were treated promptly by anticoagulants with complete recovery.

\section{Material}

During I954-55 nearly I 50 patients received cortisone and ACTH for various conditions. Four of those patients developed thromboembolic complications. Two patients had thromboembolism during cortisone administration, and two after termination of ACTH. These four patients developed deep venous thrombosis in the legs, followed by pulmonary embolism. Three were up and about during this episode and the one cortisone case was in bed but freely mobile, with good general condition. One patient had silent deep pelvic vein thrombosis, the existence of which

Summary of Patients Studied

\begin{tabular}{|c|c|c|c|c|c|c|}
\hline Case No. & Age & Sex & Disease & Doses & Time of Thromboembolism & Outcome \\
\hline I & 57 & Male & $\begin{array}{l}\text { Landry- } \\
\text { Guillain- } \\
\text { Barré syndrome }\end{array}$ & 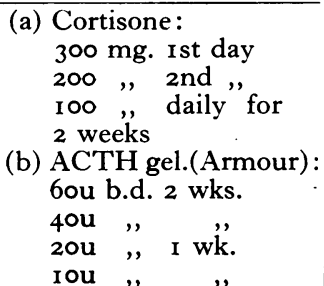 & $\begin{array}{l}\text { 5th week, after cessation } \\
\text { of ACTH; deep venous } \\
\text { thrombosis in legs and } \\
\text { pulmonary embolism }\end{array}$ & $\begin{array}{l}\text { Recovered by } \\
\text { anticoagulants }\end{array}$ \\
\hline 2 & 59 & Male & ditto & 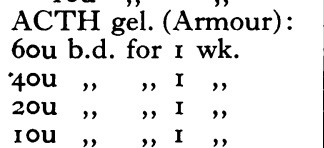 & $\begin{array}{l}\text { 2nd week after cessation } \\
\text { of ACTH; deep venuus } \\
\text { thrombosis in the legs } \\
\text { and pulmonary embol- } \\
\text { ism }\end{array}$ & ditto \\
\hline 3 & 50 & Female & $\begin{array}{l}\text { Systemic lupus } \\
\text { (pulmonary) }\end{array}$ & $\begin{array}{l}\text { ACTḦ gel. (Armour): } \\
\text { 6ou b.d. for I wk. } \\
\text { Cortisone Ioo mg. } \\
\text { daily for } 6 \text { wks. main- } \\
\text { tenance; } 25-12.5 \mathrm{mg} \text {. } \\
\text { daily for } 3 \text { months }\end{array}$ & $\begin{array}{l}\text { During Ist wk., femoral } \\
\text { vein thrombosis and pul- } \\
\text { monary embolism }\end{array}$ & $\begin{array}{l}\text { Recovered by } \\
\text { anticoagulants }\end{array}$ \\
\hline 4 & 59 & Female & $\begin{array}{l}\text { Post-adrenal- } \\
\text { ectomy state }\end{array}$ & $\begin{array}{l}\text { I.M. cortisone I,500 } \\
\text { mg. in divided doses in } \\
2 \text { weeks, pre-post- } \\
\text { operative. Oral corti- } \\
\text { sone } 50 \mathrm{mg} \text {. daily for } 4 \\
\text { weeks } \\
\text { D.O.C.A. } 350 \mathrm{mg} \text {. in } 4 \\
\text { weeks }\end{array}$ & $\begin{array}{l}\text { 6th week, thrombosis } \\
\text { deep pelvic vein (silent) } \\
\text { and pulmonary em- } \\
\text { bolism }\end{array}$ & Sudden death \\
\hline
\end{tabular}




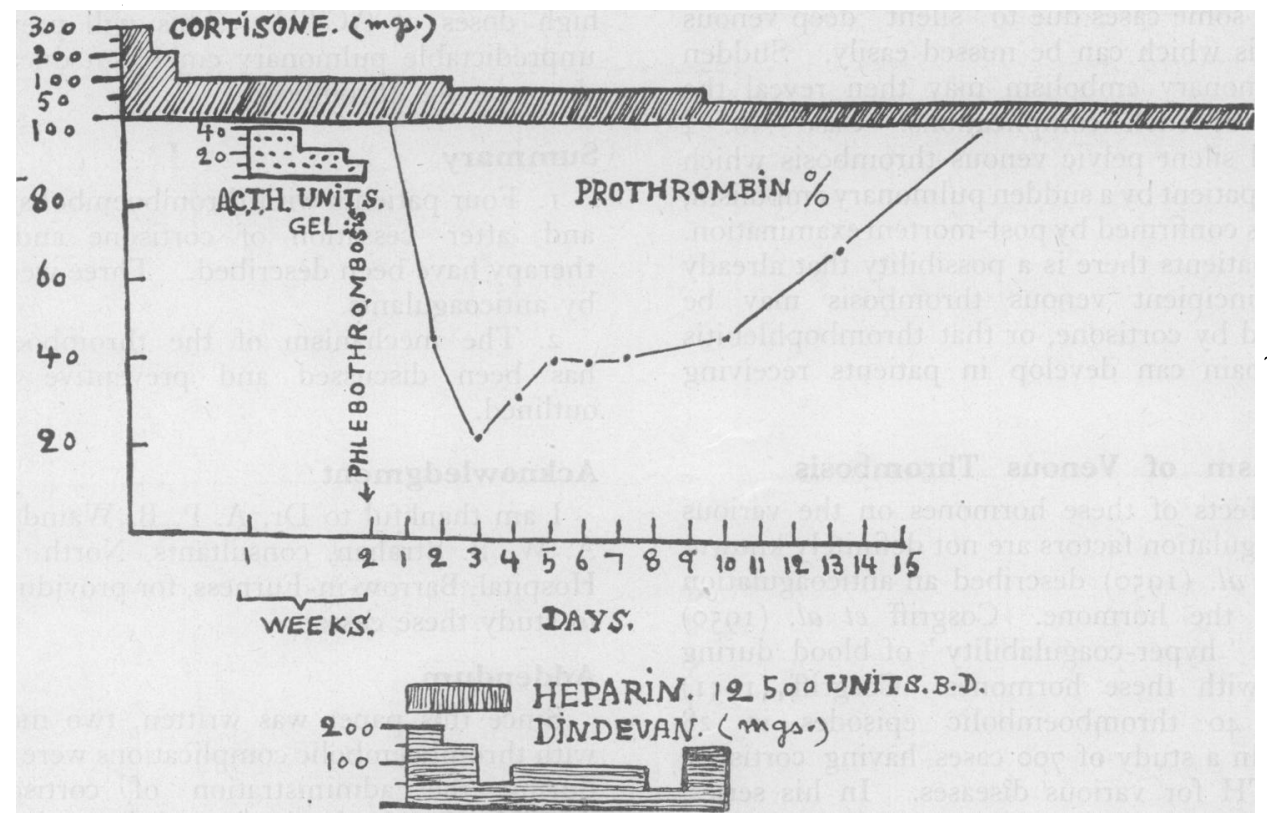

FIG. I.-Effect of ACTH and cortisone on the anticoagulants activity is shown by the plasma prothrombin behaviour in case 5 .

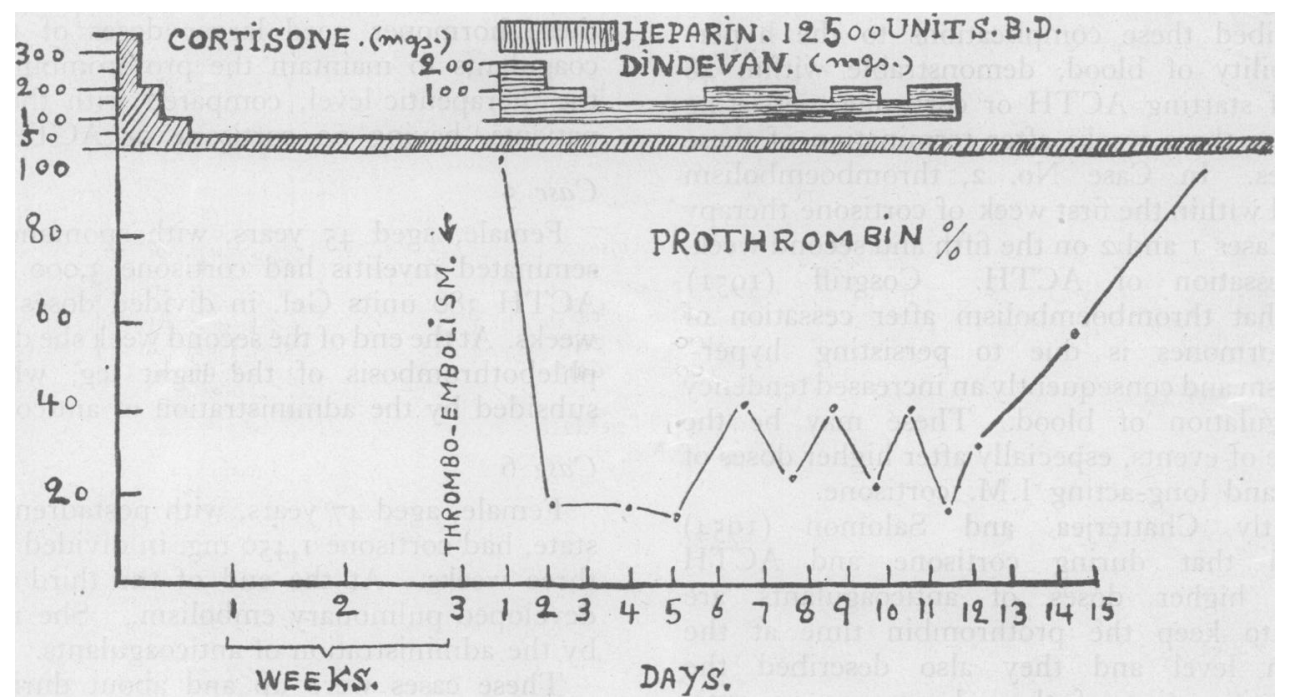

FIG. 2.-Effect of cortisone on the anticoagulants activity is shown by the plasma prothrombin behaviour in case 6 .

was revealed by post-mortem examination. She had a fatal pulmonary embolism, so suddenly that there was no time to administer anticoagulants and other supportive measures.

The age of these patients was between $5^{0-59}$ years, two were men and two women.

Onset: Two patients developed thromboembolism during cortisone therapy, one within the first week and the other in the fourth week. The other two cases manifested thromboembolism, two to five weeks after termination of ACTH (one in the second and the other in the fifth week)

\section{Discussion}

Thromboembolic complications during and after cortisone and ACTH therapy may be 
serious in some cases due to 'silent' deep venous thrombosis which can be missed easily. Sudden fatal pulmonary embolism may then reveal the existence of such ${ }^{\circ}$ complications. Case No. 4 developed silent pelvic venous thrombosis which killed the patient by a sudden pulmonary embolism, which was confirmed by post-mortem examination. In such patients there is a possibility that already existing incipient venous thrombosis may be aggravated by cortisone, or that thrombophlebitis without pain can develop in patients receiving hormones.

\section{Mechanism of Venous Thrombosis}

The effects of these hormones on the various blood coagulation factors are not definitely known. Smith et al. (1950) described an anticoagulation action of the hormone. Cosgriff et al. (1950) described ' hyper-coagulability' of blood during therapy with these hormones. Cosgriff (195I) reported 40 thromboembolic episodes in 28 patients, in a study of 700 cases having cortisone and ACTH for various diseases. In his series, these complications included deep and superficial venous thrombosis, pulmonary embolism, cerebral thrombosis and thrombophlebitis, $45 \%$ during and $55 \%$ after discontinuance of these hormones. $\mathrm{He}$ ascribed these complications to the hypercoagulability of blood, demonstrable within 48 hours of starting ACTH or cortisone, persisting as long as three weeks after termination of these hormones. In Case No. 2, thromboembolism occurred within the first week of cortisone therapy and in Cases $I$ and 2 on the fifth and second week, after cessation of ACTH. Cosgriff (I95I) thinks that thromboembolism after cessation of these hormones is due to persisting hyperadrenalism and consequently an increased tendency for coagulation of blood. These may be the sequence of events, especially after higher doses of ACTH and long-acting I.M. cortisone.

Recently Chatterjea and Salomon (1954) observed that during cortisone and ACTH therapy, higher doses of anticoagulants are needed to keep the prothrombin time at the optimum level and they also described the antagonistic action of these hormones on anticoagulants activity.

\section{Prevention}

Thromboembolic complications are liable to occur mostly in those patients with the underlying localized or generalized vascular disease, with history of previous thromboembolism, and in cases confined to bed.

It may be wise to give a course of anticoagulants as a prophylactic measure during and 3 to 6 weeks after cessation of these hormones, especially after high doses of ACTH. This will prevent fatal unpredictable pulmonary embolism due to silent deep venous thrombosis.

\section{Summary}

I. Four patients with thromboembolism during and after cessation of cortisone and ACTH therapy have been described. Three were treated by anticoagulants.

2. The mechanism of the thromboembolism has been discussed and preventive measures outlined.

\section{Acknowledgment}

I am thankful to Dr. A. P. B. Waind and Mr. A. W. B. Strahan, consultants, North Lonsdale Hospital, Barrow-in-Furness, for providing facility to study these cases.

\section{Addendum}

Since this paper was written, two more cases with thromboembolic complications were observed during the administration of cortisone and ACTH. On the institution of the anticoagulants wide fluctuation of plasma prothrombin was noted, compared with that seen in control patients, not receiving these hormones. Patients receiving these hormones need larger doses of the antio coagulants to maintain the prothrombin time as the therapeutic level, compared with the contro $\vec{c}$ patients, having no cortisone or ACTH.

\section{Case 5}

Female, aged 45 years, with spontaneous disseminated myelitis had cortisone $3,000 \mathrm{mg}$. and ACTH 380 units Gel. in divided doses for two weeks. At the end of the second week she developed phlebothrombosis of the right leg, which was subsided by the administration of anticoagulants.

\section{Case 6}

Female, aged 47 years, with postadrenalectomy state, had cortisone $\mathrm{I}, 450 \mathrm{mg}$. in divided doses for three weeks. At the end of the third week she developed pulmonary embolism. She recovered by the administration of anticoagulants.

These cases were up and about during these complications.

(I wish to record my thanks to Dr. L. Watson $\frac{D}{2}$ and Mr. J. A. Rhind, consultants, General Infirmary, Pontefract, Yorks., for allowing me to treat these cases.)

\section{BIBLIOGRAPHY}

CHATTERJEA, J. B. and SALOMON, L. (1954), B.M.F., ii, 790. COSGRIFF, S. W., DIFFENBACH, A. F. and VOGT, W. (1950), Amer. Four. Med., 9, 752.

COSGRIfF, S. W. (r951), four. Amer. Med. Assoc., 147, 924. SMITH, R. W., MARGULIS, R. R., BRENMAN, M. J. and MONTO, R. W. (1950), Science, 112, 295. 